\title{
CONSERVAR O INÍCIO DE TUDO: MAPEANDO VOZES NA CENA ENUNCIATIVA CONSERVADORA
}

\author{
Estêvão de Carvalho Freixo \\ Mestrando em Letras (Linguística) pela Universidade do Estado do Rio de Janeiro (UERJ) \\ estevaofreixo@gmail.com \\ Bruno Rêgo Deusdará Rodrigues \\ Doutor em Psicologia Social pela Universidade do Estado do Rio de Janeiro (UERJ) \\ Doutorando em Estudos da Linguagem pela Pontifícia Universidade Católica do Rio de \\ Janeiro (PUC-RJ) \\ Professor Associado de Linguística da Universidade do Estado do Rio de Janeiro (Instituto \\ de Letras/UERJ) \\ brunodeusdara@gmail.com
}

\section{RESUMO}

O presente trabalho consiste num esforço de mapeamento das possíveis alianças discursivas que acreditamos contribuírem para configuração do campo político conservadorliberal estabelecido hoje no Brasil. Para a realização dessa tarefa, utilizamos o conceito de formação discursiva, inaugurado nos trabalhos de Foucault e posteriormente revisto nos desenvolvimentos trazidos por Michel Pêcheux, entendendo que um campo político responde a um sistema particular de coerções discursivas. Além disso, aproveitamos a translinguística bakhtiniana, e a extensão que Oswald Ducrot Ihe acrescenta, a fim de desmembrar as vozes que se articulam em cada um desses sistemas discursivos, podendo, assim, melhor identificá-las em sua especificidade. Nas formulações argumentativas, observamos que um caminho frequentemente utilizado na composição lógica de enunciados correspondentes a vozes ideológicas distintas é a colaboração enunciativa por via de pontos de contato semânticos e axiológicos entre as proposições.

Palavras-chave: dialogismo, interdiscursividade, formações discursivas.

\section{ABSTRACT}

The present paper consists in an effort of mapping possible discursive alliances which we believe can contribute to the configuration of the liberal political field established in Brazil these days. For the accomplishment of this task, we used the concept of discursive formation, firstly introduced by Foucault and further developed by Michel Pêcheux, holding that a political field responds to a particular system of discursive coercions. In addition, we make use of Bakhtinian translinguistics, and Oswald Ducrot's contributions, in order to dismember voices articulated in each of these discursive systems, in order to more effectively identify them in their specificity. In the argumentative formulations, we observed that a path frequently used in the logical composition of statements corresponding to distinct ideological voices is the enunciative collaboration through semantic and axiological points of contact between propositions.

Keywords: dialogism, interdiscursivity, discursive formations. 


\section{Introdução}

A atual crise política e econômica em que o país se encontra resultou, desde as jornadas de junho de 2013, num envolvimento maior da população no debate político, por meio de manifestações espontâneas de setores populares nas ruas e do ativismo virtual nas redes sociais. Tal envolvimento produziu deslocamentos importantes na cena nacional, que ainda estão sendo submetidos à análise. Os discursos, que naquele momento estavam em ebulição, não mantinham uma intenção clara e se expressavam em suas pautas genéricas, sem compromisso estreito com este ou aquele campo político. Com o tempo, foram tomando forma mais definida, a partir do diálogo com a política partidária e outros setores da sociedade que possuíam uma direção programática já consolidada.

A partir das eleições presidenciais em 2014, o discurso político-ideológico, tanto no senso comum quanto nos domínios especializados, foi cristalizando-se na oposição formada por dois polos com vontades e projetos antinômicos. Grosso modo, um lado fazse agora representar pelos partidos de esquerda e os movimentos sociais que defendem os direitos das minorias, e o outro, pelos partidos liberais e as camadas mais conservadoras da sociedade, em especial o cristianismo evangélico, que compõe hoje uma frente parlamentar no Congresso Nacional.

O aprofundamento do entendimento desses campos em antagonismo tem a intenção de deslocar a leitura de seus enunciados da usual interpretação que cada campo faz a partir de suas próprias fórmulas cristalizadas, abrindo espaço para a relativização da alteridade e para o reconhecimento do outro enquanto sujeito de motivação legítima. 
Assim, a fim de dar conta da realização deste empreendimento, ocupar-nos-emos neste trabalho de identificar as vozes que se articulam colaborativamente na composição do campo político conservador-liberal brasileiro, guardando, assim, o exame da heterogeneidade discursiva dos campos nos quais se inscrevem seus possíveis ou potenciais antagonistas para uma oportunidade futura. Mais especificamente, buscaremos (1) inferir, a partir dos indícios presentes na materialidade do texto, a presença dos diferentes enunciadores que os locutores organizam na estrutura de suas falas, e procuraremos (2) distinguir os mecanismos enunciativos que tornam possíveis as relações de aliança entre eles estabelecidas.

Como córpus de análise, selecionamos a fala do deputado Marco Feliciano, filiado atualmente ao partido Podemos (PODE), proferida durante o programa Fla-flu, da TV Folha, que foi publicado no dia 1/07/2016, no site da Folha, sendo veiculado posteriormente na TV Cultura. O material discursivo produzido pelo parlamentar foi coletado a partir da transcrição de um fragmento do vídeo, extraído de seu compartilhamento posterior no site Youtube. O trecho transcrito foi aquele temporalmente especificado na janela de exibição do vídeo com início e fim no segmento de intervalo entre 1:21 a 2:33.

A escolha do nosso material deve-se sobretudo a duas razões. A primeira delas diz respeito ao gênero discursivo em que se apresenta. Situando-se entre o formato veiculado na internet - de duração reduzida e aberto à interferência dos espectadores - e o modelo televisivo - com estrutura de entrevista e debate -, o programa assume uma modalidade híbrida de circulação: assume contornos "classicamente" identificados com a esfera televisiva e, simultaneamente, antecipa sua circulação nas redes sociais. Nesse sentido, torna-se uma amostra especialmente representativa do nosso objeto, uma vez 
que participa de espaços onde circulam textos que contribuem de modo privilegiado para a configuração dos campos discursivos constitutivos da polarização política brasileira.

O segundo motivo está relacionado à estrutura contrastiva em que esse projeto midiático é concebido. A opção de se tomar a relação entre os espectros políticos por uma "grande competição" é anunciada desde o título do programa, com a menção a um dos jogos tidos como "clássicos" das disputas de futebol entre clubes do Rio de Janeiro: o Fla-Flu. Essa analogia inicial, que remete ao universo dos campeonatos futebolísticos, faz ainda supor outras comparações que dela decorrem, como a presença dos times e das torcidas. Assim, em que pese os riscos de se assumir uma oposição já dada por essas condições de produção discursiva - e nada impede que tal oposição seja relativizada durante o exercício de análise -, esse formato, que estrategicamente aloca os entrevistados lado a lado, de modo a contrapor seus argumentos sobre os temas políticos levantados pelo mediador, favorece a observação e o exame das falas pelo efeito de contraste que se produz entre os enunciados.

Como resultado da análise, identificamos como extrato auxiliar e suporte axiológico ao pensamento conservador-liberal o discurso cristão-conservador. Acreditamos que essa formação discursiva seja constituída a partir das práticas ideológicas que funcionam no interior da tradição católica e do movimento evangélico brasileiro. Verificamos, além disso, a presença do ponto de vista contratualista no campo do conservadorismo-liberal, aliando-se ao discurso cristão em sua preocupação com a preservação dos princípios norteadores e reguladores que teriam sido estabelecidos no marco inicial da vida social (caso contratualista) ou da própria existência humana (caso cristão). Com efeito, sublinhamos que não por acaso a corrente contratualista e o liberalismo político demonstram sua compatibilidade quando aparecem alinhados nos 
trabalhos desenvolvidos, por exemplo, pelos filósofos John Locke e Jean-Jacques Rousseau durante o século das luzes. Finalmente, percebemos que um caminho notadamente frequente utilizado na composição lógica de enunciados identificados com posicionamentos distintos é a colaboração enunciativa por via de pontos de contato semânticos e axiológicos entre diferentes proposições. Tais pontos, formando-se na recorrência de dadas entidades linguísticas no encadeamento enunciativo, parecem funcionar como mecanismos de coesão a manter interligadas as estruturas argumentativas compostas pelos posicionamentos configuradores do campo discursivo em análise.

\section{A heterogeneidade disciplinar do discurso político}

O fenômeno político é especialmente producente para a compreensão do conceito de formação discursiva, em razão da heterogeneidade disciplinar que entendemos ser-lhe característica. Enumeramos aqui alguns pontos de vista, a fim de apresentar esse fenômeno como campo discursivo produzido mediante o encontro de diferentes vozes. Na teoria foucaultiana, o discurso que configura esse campo dialoga com outros que dele se distinguem nos diferentes critérios de agrupamento enunciativo. Entende o filósofo que tipos institucionalizados como a política - bem como a literatura, a filosofia, a ciência - "são (...) fatos de discurso que merecem ser analisados ao lado dos outros, que com eles mantêm, certamente, relações complexas, mas que não constituem seus caracteres intrínsecos, autóctones e universalmente reconhecíveis" (FOUCAULT, 2000, p. 25). 
De outro ângulo, Patrick Charaudeau (2006) sublinha que "não há domínio reservado, exclusivo, para a análise do fenômeno político, como alguns poderiam pretender", sendo ele o resultado de um conjunto de fatos que pertencem a diferentes ordens que se entrecruzam constantemente. E para ilustrar sua asserção, evoca Claude Le Fort, que enumera essas dimensões como fatos políticos, sociais, jurídicos e morais.

Finalmente, o linguista francófono Dominique Maingueneau, em sua apresentação dos discursos constituintes, cuja pretensão é a de legitimar a totalidade da produção discursiva em uma sociedade, e entre os quais se incluem o discurso da ciência, da religião, da filosofia, etc., esclarece que o discurso político não se inclui entre eles, porquanto ele próprio neles se apoia. Dado que os discursos constituintes são aqueles que dão sentido aos atos da coletividade, o discurso produzido no campo político os invoca "para fazê-los entrar em relação com os lugares comuns de uma sociedade" (MAINGUENEAU, 2000).

\section{A formação discursiva em Michel Pêcheux}

A partir da sua filiação com o marxismo althusseriano, Pêcheux desenvolve o conceito de formação discursiva com esteio em base teórica diretamente implicada com o conceito crítico de ideologia, preparando e fundamentando sua acepção de formação discursiva a partir das noções de formação social e formação ideológica, que são proposições de cariz sociológico. Entende o filósofo que a formação social se caracteriza por um modo de produção dominante em dado momento histórico e que, nessas condições, as relações entre as classes se expressam em consequência da hierarquia existente nas práticas que sustentam esse modo de produção. A essas relações 
correspondem posições políticas e ideológicas, que se organizam em formações as quais mantêm entre si nexos de antagonismo, aliança ou dominação.

Nesse contexto, as formações ideológicas devem ser entendidas como a manifestação das forças de matriz sociopolítica que, confrontadas a outras, intervêm na conjuntura ideológica própria à formação social de um dado momento histórico (HAROCHE; HENRY; PÊCHEUX, 1971). Assim, essas formações ideológicas se materializam no discurso por meio de uma ou várias formações discursivas interligadas, que determinam o que pode e deve ser dito, independentemente do gênero discursivo em que esse dizer seja articulado. Mas não só as palavras estão sujeitas a esse jogo seletivo, como também as "construções nas quais essas palavras se combinam, na medida em que elas determinam a significação que tomam essas palavras: (...) as palavras mudam de sentido segundo as posições ocupadas por aqueles que as empregam" (HAROCHE; HENRY; PÊCHEUX, 2007, p. 26).

Sendo assim, na relação entre base linguística e processo discursivo-ideológico, o sentido das palavras, das expressões ou das proposições não está vinculado à sua literalidade, mas varia conforme estas façam referência a uma ou outra formação discursiva (PÊCHEUX, 1995).

\section{Bakhtin e o princípio dialógico da linguagem}

A partir do final do século XIX, os fenômenos da linguagem começam a desempenhar um papel central na filosofia. Na década de 20 do século seguinte, o filósofo Mikahil Bakthin imagina uma ciência que se ocupasse do exame das relações dialógicas que os enunciados mantêm entre si, atribuindo essa tarefa à ciência da 
translinguística. Fiorin (2016) nos explica que, para o autor russo, a noção de dialogismo é constitutiva da linguagem. Nesse sentido, todos os enunciados no processo de interação constituem uma dimensão dialógica. Em contraposição às unidades da língua - base material que permite a comunicação e circulação de ideias - os enunciados dizem respeito ao funcionamento real do sistema linguístico. Além disso, sendo o caráter dialógico a propriedade que distingue a unidade enunciativa da unidade da língua, a dimensão de um enunciado não seria verificada por meio dos limites de sua extensão, mas teria por critério de medida a sucessiva alternância entre os falantes na sequência da cadeia discursiva.

\section{Ducrot e a teoria polifônica da enunciação}

Segundo Ducrot (1987), o pressuposto da unicidade do sujeito, que atribui a responsabilidade pela produção de cada enunciado a um único sujeito, durou longo tempo na teoria literária, não sendo contestado senão a partir da teoria bakhtiniana, que reconhece, numa certa categoria de textos, classificados como polifônicos, a ocorrência simultânea de vozes distintas sem que uma das vozes prepondere sobre as demais.

A fim de preparar a apresentação de sua própria teoria da polifonia, Ducrot estabelece algumas distinções e ressignifica alguns conceitos de uso corrente na linguística enunciativa. A enunciação é definida pelo autor como "o acontecimento constituído pelo aparecimento do enunciado" (DUCROT, 1987, p. 168), sua realização histórica. Paralelamente à oposição entre frase e enunciado, Ducrot apresenta também seus correspondentes: significação e sentido. Esse estudioso entende por significação a caracterização semântica da frase e por sentido a caracterização semântica do enunciado. 
A significação traria em sua estrutura léxico-gramatical um conjunto de instruções a partir das quais se poderia associar um sentido ao enunciado, que, para Ducrot, consistiria precisamente na descrição da enunciação. A esta última, então, poderiam ser atribuídos "um ou vários sujeitos que seriam sua origem" (DUCROT, 1987, p. 182). Entre esses sujeitos que o enunciado indica como fontes da enunciação, Ducrot distingue dois tipos de personagens: enunciadores e locutores. O locutor seria aquele que se apresenta como responsável pelo enunciado, o ser do discurso a quem fariam referência o pronome eu e as demais marcas de primeira pessoa, e não coincidiria necessariamente com o autor empírico do enunciado. Os enunciadores, por sua vez, seriam aqueles que têm seu ponto de vista expresso na enunciação, sem que lhes fossem atribuídas palavras precisas. 0 locutor, portanto, pode manifestar sua posição, porque se assimila a este ou aquele dos enunciadores, tomando-os como representantes (DUCROT, 1987).

Para Ducrot, o sentido do enunciado não remete necessariamente a uma fonte e a um alvo, de modo que a alusão à figura do autor não the é forçosamente inerente. Tomemos o exemplo das vozes de grande amplitude consideradas na teoria bakhtiniana. Há casos em que não se poderá apontar um sujeito empírico responsável por um enunciado que expressa uma voz social, mas isso não significa que as regras de formação pelas quais se constitui, tais como o seu vocabulário conceitual e o seu posicionamento ideológico, não possam ser analisados discursivamente. O ponto de vista neles expresso, isto é, seus enunciadores, podem ser reconhecidos mediante o exame dos indícios que apontam para seus discursos fundadores. E é nesse sentido que nos parece ser possível sugerir que, ao estudarmos as formações discursivas, podemos tomar para nós, como aventou Ducrot, a tarefa de especificar, por via das indicações presentes no sentido do enunciado, as fontes cujos pontos de vista são expressos nos enunciados analisados. 


\section{Análise}

FC - Muitas pessoas afirmam que houve uma estratégia de domínio da parte do ex-presidente da Câmara, o Eduardo Cunha, pra colocar projetos nas comissões de interesse de uma pauta que seria uma pauta conservadora (...) queria abrir aí o Fla-flu então, pedir primeiro as considerações do Marco Feliciano com a seguinte pergunta: há de fato uma pauta conservadora, retrógrada, como muita gente diz, avançando no congresso?

MF - (...) Todas as vezes que [se] fala sobre conservadorismo e alguém fala o que você chamou de retrógrado isso é horrível de se ouvir, né? Eu venho de uma época que minha mãe dizia que tudo que fica em conserva dura mais tempo, né? Então conservadorismo é aquilo que conserva o início de tudo, né? E principalmente da/na existência de uma sociedade.

Nesta seleção, o mediador Fernando Canzian dá início ao debate, colocando em cena um ponto de vista crítico ao posicionamento conservador, enquanto dirige uma pergunta ao deputado Marco Feliciano: "há de fato uma pauta conservadora, retrógrada, como muita gente diz, avançando no congresso?". Destaque-se, a esse respeito, a identificação que se estabelece entre o conservador e o retrógrado, resultando em uma avaliação negativa do que se tematiza. Ao lado desse movimento, observe-se que o locutor, no entanto, não se assimila integralmente ao ponto de vista enunciado, já que dele se distancia pela indicação de uma fonte na qual não se inclui: "como muita gente diz". Em sua resposta, o deputado desloca o sentido da expressão "conservadorismo", na medida em que recupera o termo, expressando-o a partir de sua posição ideológica. A associação feita entre as posições conservadora e retrógrada é rejeitada, e o conceito de conservadorismo é então retomado a partir de três enunciadores distintos.

O primeiro enunciador, chamaremos de discurso da tradição familiar, justificandonos com base em duas indicações presentes no enunciado. Diz o deputado: "Eu venho de 
uma época que minha mãe dizia que tudo que fica em conserva dura mais tempo, né?". A respeito do uso de provérbios como fenômeno enunciativo da heterogeneidade mostrada, Maingueneau entende coincidir o locutor que o valida com "o conjunto de falantes da língua, estando aí incluído o indivíduo que o profere" (MAINGUENEAU, 1997, p. 101). Assim, assumiremos que, nesse caso, a fonte enunciativa da fala do deputado é a própria memória coletiva. E porque sua fala expressa o desejo de preservação dessa memória, entendemos que o locutor quer situar o conservadorismo no lugar do respeito à tradição. Mas o conceito de tradição pode estar ligado à transmissão de saberes e costumes em diferentes esferas da vida social, pode se referir a diferentes matizes culturais ou variadas formas de crença. Nesse sentido, a tradição a que o locutor faz alusão parece estar vinculada à experiência no seio de um modelo familiar particular no qual o locutor se vê inserido - conclusão a qual chegamos pela reverência dirigida às palavras de sua mãe.

O segundo enunciador, cujo posicionamento reconhecemos como cristãoconservador, faz-se entrever pelo indício fraco e sutil do sintagma "o início de tudo": "Então conservadorismo é aquilo que conserva o início de tudo, né?". A indefinição do pronome tudo, nesse contexto, em que se requer a particularização daquilo que é conservado, esvazia consideravelmente o sentido do enunciado, de modo que o uso da palavra não se vê convenientemente justificado. Certamente "tudo" nesse enunciado não é uma recuperação desse vocábulo no enunciado anterior ("tudo que fica em conserva"), pois, nesse caso, o pronome claramente indica a indefinível variedade de alimentos que podem ser preservados em conserva. Sabemos, além disso, que a palavra "tudo" não faz aí referência à ideia de sociedade - logo, provavelmente também não o faz à civilização, potencial sinonímia da anterior - já que a expressão "sociedade" é acrescida a seguir no 
fragmento "E principalmente da / na existência de uma sociedade". O sentido da segunda utilização do vocábulo "tudo", portanto, fica na sombra, deixando entrever apenas que é um tudo do qual se fala sobre sua gênese. Ficamos, assim, sem qualquer indício no enunciado acerca do sentido dessa palavra e teríamos dificuldade em interpretá-la, a não ser que recorrêssemos à circunstância extralinguística a seguir apresentada, a fim de proceder à sua análise num plano de validade hipotética. Assim, se levamos em conta a filiação que o deputado e pastor abertamente expressa em suas entrevistas ao ponto de vista criacionista, podemos supor que o uso da expressão "o início de tudo" traz uma referência implícita à narrativa cosmogônica cristã - o início da vida, da Terra, do universo. De toda forma, se tal hipótese é válida, precisamos ainda nos perguntar sobre o motivo do apagamento desse sentido no enunciado. Para responder a essa questão, consideraremos a frequente reafirmação da constitucionalidade do Estado laico pelo posicionamento progressista em resposta a certos avanços dos setores religiosos, por entender haver imiscuição dos princípios cristãos no ordenamento jurídico da vida política. Assim, podemos imaginar que o deputado esteja evitando, nesse momento, explicitar um entendimento político em diálogo com a tradição judaico-cristã.

Finalmente o argumento do deputado, que contesta a associação entre o conservador e o retrógrado, chega a termo com o enunciado "E principalmente da / na existência de uma sociedade". Complementando o objeto da frase anterior: "conservadorismo é aquilo que conserva o início", esse último fragmento renova a preocupação do locutor com o problema da origem, que nesse momento é definido como aquele relativo ao início da "existência de uma sociedade". Considerando esses dois enunciadores ocupados com a temática da origem, observamos a instauração implícita de uma coordenada temporal expandida, sublinhando o destaque a um tempo que se 
inscreve por um movimento que ultrapassa a continuidade e se insere na lógica da permanência. Nessa articulação, observa-se a construção de uma dimensão moral, aquela que sustenta que uma sociedade "deveria" conservar seu início, em um tempo que reenvia constantemente para o seu passado. Tal dimensão se sustenta em uma coordenada de tempo que se pode presumir por meio da oposição construída entre "conservador" e "retrógrado". Nessa oposição, distancia-se o tempo das permanências, que é o tempo do que deveria ser mantido ou conservado; do tempo dos retrocessos, da retroação em relação a mudanças conquistadas.

Tendo realizado esse primeiro exercício de análise, em que consideramos a forma como a dimensão temporal é construída ao longo da estrutura argumentativa, resta ainda o trabalho de localização da fonte enunciativa do segmento analisado. Todavia, a forma simplificada pela qual o enunciado é produzido dificulta, tal como no caso anterior, o trabalho de situá-lo em termos de sua filiação discursiva. É importante lembrar, entretanto, que as vozes que acompanham o discurso político muitas vezes aparecem sob a vaga forma de um vestígio. Prestando-Ihe apenas como suporte, os discursos auxiliares são frequentemente evocados sob estrutura abreviada e com densidade diluída, aparecendo, inclusive, como simples alusão. E, nesse caso, não nos resta outra coisa, senão o trabalho do levantamento de hipóteses a partir de índices que, mesmo fracos em sua qualidade de marca discursiva, podem ser complementados com o auxílio de sinais recolhidos do contexto geral da enunciação e de suas adjacências, ou ainda de elementos extralinguísticos que venham contribuir com a demonstração da tese de análise sugerida.

O segmento que agora examinamos, bem como o anterior, ilustram o que acabamos de descrever como "vestígio discursivo", na medida em que o seu sentido é produzido por um efeito de esvaziamento, num enunciado sem significações bem 
delimitadas, em que o raciocínio nele construído não tem sua fonte prontamente identificável, sendo necessário atuar sobre os implícitos. E, sendo assim, buscamos desenvolver nossa hipótese de análise a partir da relação estabelecida entre os poucos vocábulos que ali se coordenam.

Dito isso, observemos que o fragmento em análise traz uma nova predicação à ideia de "conservadorismo", quando lhe define como "aquilo que conserva o início da existência de uma sociedade", em explícita contraposição em relação a "o que retrocede".

Já salientamos que, nesse caso, o locutor renova sua preocupação com a questão da origem. Entretanto, não se trata, dessa vez, de uma alusão ao texto bíblico que narra sobre a criação do mundo e de todas as coisas que nele existem. Não é o caso de uma reverência ao Criador e aos princípios por ele estabelecidos desde o início. Trata-se, por outro lado, da origem da sociedade enquanto organização político-econômico-social, estrutura formal constituída, ordenamento de convenções. Mais que isso, pressupõe-se, nesse caso, que esse momento de inauguração do processo civilizatório deve ser compreendido como um grande marco exordial, que separa um estado pré-civilizatório, natural, selvagem talvez, de um outro, onde a vida civil torna-se possível mediante o arranjo e a coordenação de um conjunto de prescrições sociais.

O apelo que se faz, portanto, e o ponto de vista que se evoca, é aquele da posição contratualista, que concebe o Estado como corpo político-administrativo fundado a partir de um grande pacto social, cujas cláusulas são tacitamente reconhecidas, sendo sempre as mesmas, independentemente do exemplo analisado.

Assim, na sociedade formalmente organizada, que marca uma ruptura definitiva com a existência humana natural, o comportamento instintivo faz-se substituir por aquele 
eticamente orientado e justo. E, sendo esse contrato a garantia fundamental de estabilidade e manutenção do corpo coletivo, qualquer modificação menor ou violação de suas normas seria capaz de promover a sua quebra, fazendo retroverter o estado civilizado, fundado nas convenções, àquele da liberdade natural e selvagem. Nesse sentido, portanto, o "início da existência de uma sociedade" haveria de ser preservado, sob pena da dissolução de toda estrutura reguladora e convencional que mantém o Estado em funcionamento.

O que se vê, portanto, é que os três enunciadores apresentados pelo locutor fazem referência a um tempo pretérito, prescrevendo a necessidade de preservação daquilo que se estabeleceu nesse tempo primordial. Em cada um dos discursos, essa referência se inscreve por meio das marcas que lhes são distintivas: no primeiro, por via da ideia de tradição; no segundo, pelo sintagma "o início de tudo"; no terceiro, pela referência à origem da sociedade. Assim, os três enunciadores, discursos distintos que obedecem a diferentes regras de formação, articulam-se dentro de uma formação discursiva maior, de modo a colaborarem entre si para a defesa do ponto de vista desse campo dentro do qual eles formam suas alianças.

Destacaremos também que as falas apresentadas por cada um desses enunciadores só puderam estabelecer as relações lógico-argumentativas necessárias à defesa do ponto de vista final, mediante a seleção de certos vocábulos ou sintagmas, cujas aproximações semânticas puderam garantir a coesão necessária à manutenção do tema enunciativo. Como antes apontamos, a presença dos valores "passado" e "preservação" foram representados em cada um dos discursos por diferentes elementos ou conjuntos lexicais (1ํ enunciador: "eu venho de uma época", "dura mais tempo"; 2o enunciador: "conserva", "o início de tudo"; 3o enunciador: "conserva”, "o início da / na 
existência de uma sociedade"). Se, por um lado, a escolha dessas marcas representa a construção de equivalências semânticas entre os enunciadores arrolados, por outro, corresponde também à formação de uma identidade de valores, visto que os termos "passado" e "preservação", além de se referirem a significados particulares, podem também expressar, e nesse caso efetivamente expressam, princípios éticos que podem participar de diferentes sistemas axiológicos.

Em conclusão, portanto, diremos que as relações de aliança estabelecidas entre os enunciadores asseguraram a construção lógica da estrutura argumentativa organizada na fala do locutor, a partir do estabelecimento de dois pontos de contato entre os segmentos encadeados. Esses pontos de contato, ou elos coesivos, que correspondem aos significados "passado" e "preservação", constituem juntos o princípio ético da "preservação do passado", e, por força de sua recorrência nos três enunciadores, garantiram de um lado, a coesão semântica mantenedora da unidade temática e, de outro, o estabelecimento de uma base axiológica orientadora do fio discursivo.

\section{Considerações finais}

Em nosso exercício de análise, identificamos a presença da tradição judaico-cristã como extrato auxiliar e suporte axiológico ao pensamento conservador-liberal. Esperávamos encontrar, como base de apoio cientificista, algum exemplo demonstrativo do auxílio do discurso positivista ao polo da direita, o que nos pareceu uma ocorrência muito comum durante o processo de definição do nosso recorte empírico. Para esse objetivo, nosso córpus se mostrou escasso em sua qualidade de amostra, e entendemos que seria importante a realização de uma análise aplicada a outro material a fim de 
demonstrar mais claramente a articulação entre os discursos liberal e o cientificismo positivista.

Verificamos também a colaboração de um ponto de vista contratualista no campo da direita, que parece se aliar ao discurso cristão, alimentando a preocupação com a preservação dos princípios reguladores supostamente estabelecidos no marco inicial da vida social ou da própria existência humana. Essa preocupação em se conservar esses preceitos inaugurais parece implicar algum tipo de risco estrutural ou prenúncio de mau acontecimento na hipótese de sua violação. Trata-se, em ambos os casos, de se preservar o que se estabelece num "início" - um grande evento constituinte, formador e estruturante da vida humana ou da sociedade - para não se incorrer na fatalidade de um "fim" - a hipótese da desintegração ou da dissolução desses fenômenos inaugurados. Para o enunciador contratualista é possível supor que a ameaça consiste na extinção da vida social organizada; o perigo é o do retorno ao estado natural da vida humana. No discurso cristão, por outro lado, o temor que se instaura pode ser - e aqui especulamos, a fim de levar a termo o paralelismo do binômio início-fim que se expressa nos dois casos analisados, - o da proximidade de um desfecho apocalíptico. Expressões como "é o fim do mundo", "é o final dos tempos", comumente lançadas por um olhar cristãoconservador quando da observação de comportamentos ditos desviantes (para esse campo discursivo), poderiam aqui ser evocadas para sustentar essa suposição. Finalmente, sublinhamos que a identificação no córpus dos enunciadores cristão e contratualista demandou-nos o levantamento de hipóteses construídas a partir da correlação dos segmentos com o contexto geral da enunciação e com elementos extralinguísticos, vez que, apresentados sob a vaga forma de um "vestígio discursivo", 
com estrutura abreviada e densidade diluída, esses discursos auxiliares tornaram difícil o exame de sua filiação.

Um achado que nos suscitou especial interesse na realização deste trabalho decorreu da observação do modo como diferentes pontos de vista são usualmente organizados na fala de um locutor. Percebemos que um caminho notadamente frequente utilizado na composição lógica de enunciados identificados com posicionamentos distintos é a colaboração enunciativa por via de pontos de contato semânticos e axiológicos entre diferentes proposições.

Em linhas finais, aproveitamos para sublinhar que este exercício de mapeamento das diferentes vozes que se articulam colaborativamente na composição de cada um dos campos discursivos da polarização política sugere a possibilidade da realização de estudos mais especializados de cada um dos extratos identificados como auxiliares das formações discursivas dominantes em cada um desses campos. Outras amostras poderiam mostrarse particularmente produtivas para, por exemplo, estabelecer melhor discriminação dos discursos científicos que formam aliança com cada um dos polos, situando-se mais precisamente os eixos paradigmáticos e epistemológicos com os quais se comunicam.

\section{Referências}

CHARAUDEAU, Patrick. O discurso político. In: EMEDIATO, W.; MACHADO, I. L.; MENEZES, W. (orgs.). Análise do discurso: gêneros, comunicação e sociedade. Belo Horizonte: NAD, POSLIN, FALE-UFMG, 2006. p. 251-268.

DUCROT, Oswald. O dizer e o dito. Campinas, SP: Pontes, 1987 (1984).

FIORIN, J. L. Introdução ao pensamento de Bakhtin. São Paulo: Ática, 2016. 
FOUCAULT, Michel. A arqueologia do saber. 6. ed. Rio de Janeiro: Forense Universitária, 2000 (1969).

HAROCHE, C.; HENRY, P.; PÊCHEUX, M. A semântica e o corte saussuriano: língua, linguagem, discurso. In: BARONAS, R. L. Análise do Discurso: apontamentos para uma história da noção-conceito de formação discursiva. São Carlos, SP: Pedro \& João Editores, 2007.

MAINGUENEAU, Domenique. A heterogeneidade mostrada. In: MAINGUENEAU, Domenique. Novas tendências em análise do discurso. 3. ed. Campinas, SP: Pontes, 1997 (1987). p. 75-109.

MAINGUENEAU, Dominique. Analisando discursos constituintes. Revista do Gelne, Natal, v. 2 , n. $1 / 2$, p. 1-12, 2000.

PÊCHEUX, Michel. Semântica e discurso: uma crítica à afirmação do óbvio. Campinas, SP: Editora da UNICAMP, 1995.

Recebido em 22 de dezembro de 2017.

Aceite em 18 de março de 2018. 